\title{
The Added Value of a Vasculitis Clinic in a Tertiary Referral Hospital
}

\author{
A Mais-Valia de uma Consulta de Vasculites num \\ Hospital Terciário
}

Nikita KHMELINSKII ${ }^{1}$, Maria Inês SEIXAS ${ }^{1}$, Cristina PONTE ${ }^{1,2}$, João Eurico FONSECA ${ }^{1,2}$, Carla MACIEIRA ${ }^{1}$ Acta Med Port 2018 Nov;31(11):614-617 $\cdot$ https://doi.org/10.20344/amp.9875

\begin{abstract}
Keywords: Outpatient Clinics, Hospital; Referral and Consultation; Registries; Tertiary Care Centers; Tertiary Healthcare; Vasculitis Palavras-chave: Ambulatório Hospitalar; Centros de Cuidados Terciários; Cuidados de Saúde Terciários; Encaminhamento e Consulta; Registos; Vasculites
\end{abstract}

\section{INTRODUCTION}

The vasculitides represent a group of uncommon conditions, with a wide range of manifestations, characterized by inflammation of blood vessels. Its incidence in the Portuguese population is still unknown. EpiReumaPt - the first large epidemiologic study of rheumatic diseases in Portugal - was not powered to detect low prevalence diseases, such as vasculitis. ${ }^{1}$

The aetiology of vasculitis remains unknown, but is likely to be multifactorial, involving genetic and environmental aspects. The vasculitides are frequently organ- or life-threatening conditions, but due to their rarity and heterogeneous manifestations the diagnosis and management still remains a challenge.

In 2011, the Rheumatology Department of Hospital de Santa Maria established a dedicated outpatient clinic for patients with vasculitis. In 2014, this outpatient clinic gave a major contribution to the creation of a specific module to register patients with vasculitis in Reuma.pt (the Portuguese registry of rheumatic diseases). ${ }^{2,3}$

We aim to describe the general functioning of our vasculitis outpatient clinic; to retrospectively review the demographics, diagnosis and treatment of all patients with systemic vasculitis followed at the clinic and registered in Reuma.pt/Vasculitis; to mention the assessment tools and protocols used in the different subtypes of vasculitis; and to list the research studies or initiatives we have participated or are currently being undertaken.

\section{VASCULITIS OUTPATIENT CLINIC Description}

Our vasculitis clinic is managed by two Rheumatologists and by one to two Rheumatology residents on a weekly basis. It is a multidisciplinary clinic where various medical specialties collaborate closely with regular discussion of selected cases. In addition, we are responsible for monthly combined clinics with Dermatology, to discuss vasculitis cases with skin involvement, and with Ophthalmology, to assess eye involvement in patients with giant cell arteri- tis (GCA) and eye inflammation in other vasculitides (e.g. Behçet's disease). We also provide a fast-track approach to all patients with suspected GCA, with clinical and ultrasound assessment in less than 48 hours. Patients who need to start biological therapies are discussed in our general department meeting and then systematically monitored in the day-care unit.

All our patients with the final diagnosis of vasculitis are registered in Reuma.pt/Vasculitis and blood is collected for storage at the Biobanco-IMM, Lisbon Academic Medical Centre.

Procedures for optimized standard-of-care and outcomes expected for quality assessment (e.g. decrease in disease- or treatment-related complications) are defined in an official document produced by our department and applied in our clinic.

\section{Experience}

A total of 163 patients were followed between October 2011 and January 2017. There were 111 (68\%) women and $52(32 \%)$ men, with a mean age of $57 \pm 18$ (range $19-87$ ) years at the last visit. Clinical data was available for analysis on 831 outpatient visits. Mean time of follow-up was 1.3 \pm 1.5 (range 0 - 5.2) years. Patients' referrals came from General Rheumatology $(n=61)$, General Practitioner $(n=$ $19)$, Neurology $(n=17)$, Ophthalmology $(n=12)$, Vascular Surgery $(n=9)$, Internal Medicine $(n=9)$, Otorhinolaryngology $(n=8)$, Emergency $(n=7)$, Dermatology $(n=6)$, Immuno-allergology $(n=4)$, Nephrology $(n=3)$, Infectious Diseases $(n=2)$, and other medical specialties (one patient each; $n=6)$.

Patients' diagnoses were based on the 2012 International Chapel Hill Consensus Conference nomenclature. ${ }^{4}$ From the initial cohort of 163 patients, 114 patients had the final diagnosis of vasculitis. Ninety-three patients had a diagnosis of systemic vasculitis and are further analysed in Table 1. From the remaining 21 patients with vasculitis, 11 had single-organ vasculitis [cutaneous $(n=5)$, central nervous system $(n=3)$, retinal $(n=2)$, and bladder $(n=1)]$,

\footnotetext{
1. Rheumatology Department. Hospital de Santa Maria. Centro Hospitalar Lisboa Norte. Lisbon Academic Medical Centre. Lisbon. Portugal.

2. Rheumatology Research Unit. Instituto de Medicina Molecular. Faculty of Medicine. University of Lisbon. Lisbon. Portugal.

$\triangle$ Autor correspondente: Nikita Khmelinskii.nkhmelinskii@gmail.com.

Recebido: 30 de outubro de 2017 - Aceite: 17 de agosto de 2018 | Copyright @ Ordem dos Médicos 2018
} 
nine had vasculitis associated with systemic disease [systemic lupus erythematosus $(n=3)$, Sjögren's syndrome ( $n$ $=3$ ), overlap syndrome $(n=1), Q$ fever $(n=1)$, and solid cancer $(n=1)]$, and one had drug-associated vasculitis to methimazole.

A total of 49 patients were not confirmed to have a final diagnosis of vasculitis. The most common 'other diagnoses' were idiopathic sensorineural hearing loss $(n=9)$ and cardioembolic/atherosclerotic disease $(n=4)$.

Immunosuppressive treatment is detailed in Table 1. Four patients were treated with biologic disease-modifying anti-rheumatic drugs (DMARDs), after failure to achieve remission with corticosteroids and synthetic DMARDs: a patient with Takayasu's arteritis (TAK) with progression of the vascular lesions was treated with infliximab; another patient with TAK with severe extracranial disease and new-onset retinal vasculitis was treated with tocilizumab; a patient with early-onset polyarteritis nodosa (PAN), associated with adenosine deaminase 2 deficiency, with central and peripheral nervous system involvement was treated with infliximab; a patient with microscopic polyangiitis with sensorimo- tor axonal polyneuropathy was treated with rituximab.

Eight patients with systemic vasculitis were lost to follow-up, four were discharged and two died (one patient with GCA due to septic arthritis and another with TAK due to postoperative sepsis).

\section{Outcomes assessment}

The increased clinical trial activity in vasculitis, along with its heterogeneity, has led to the development and validation of several disease assessment tools. The Outcome Measures in Rheumatology (OMERACT) Vasculitis Working Group has approved a core set of instruments in AN$\mathrm{CA}$-associated vasculitis (AAV) to assess disease activity (Birmingham Vasculitis Activity Score [BVAS] and BVAS for Wegener's granulomatosis), damage (Vasculitis Damage Index [VDI]) and prognosis (five-factor score). ${ }^{5}$ We have been applying this core set to all patients with AAV and PAN (Table 1) and provided specific training and certification for the correct assessment of BVAS and VDI during the Portuguese Society of Rheumatology Vasculitis Workshop meeting (January 2015), where the Reuma.pt/Vasculitis module

Table 1 - Demographics, clinical manifestations, complementary tests findings, assessments and treatment of the patients with a diagnosis of systemic vasculitis categorized according to vessel size

\begin{tabular}{|c|c|c|c|c|c|c|c|}
\hline & \multicolumn{2}{|c|}{ LVV } & \multirow{2}{*}{$\begin{array}{l}\text { MVV } \\
\text { PAN } \\
n=5\end{array}$} & \multicolumn{2}{|c|}{ SVV * } & \multicolumn{2}{|c|}{ VVV } \\
\hline & $\begin{array}{c}\text { GCA } \\
n=34\end{array}$ & $\begin{array}{c}\text { TAK } \\
\mathrm{n}=12\end{array}$ & & $\begin{array}{c}\text { AAV } \\
n=16\end{array}$ & $\begin{array}{c}\text { Other SVV } \\
n=7\end{array}$ & $\begin{array}{c}\mathrm{BD} \\
\mathrm{n}=18\end{array}$ & $\begin{array}{c}\text { CS } \\
n=1\end{array}$ \\
\hline \multicolumn{8}{|l|}{ Demographics } \\
\hline Mean age at onset, years (SD) & $75(7)$ & $26(12)$ & $36(24)$ & $51(17)$ & $30(20)$ & $24(15)$ & 26 \\
\hline Female (\%) & $18(53)$ & $11(92)$ & $4(80)$ & $14(88)$ & $2(29)$ & $13(72)$ & $1(100)$ \\
\hline \multicolumn{8}{|l|}{ Clinical manifestations $(\%)^{\dagger}$} \\
\hline $\begin{array}{l}\text { General } \\
\text { Constitutional } \\
\text { Musculoskeletal }\end{array}$ & $\begin{array}{l}29(85) \\
19(56)\end{array}$ & $\begin{array}{l}7(58) \\
3(25)\end{array}$ & $\begin{array}{c}5(100) \\
3(60)\end{array}$ & $\begin{array}{l}7(44) \\
6(38)\end{array}$ & $\begin{array}{l}3(43) \\
3(43)\end{array}$ & $\begin{array}{c}4(22) \\
10(56)\end{array}$ & $\begin{array}{l}1(100) \\
1(100)\end{array}$ \\
\hline Cutaneous & & $1(8)$ & $5(100)$ & $6(38)$ & $7(100)$ & $16(89)$ & $1(100)$ \\
\hline $\begin{array}{l}\text { Mucous membranes / Eyes } \\
\text { Mucosal } \\
\text { Ocular }\end{array}$ & 21 (62) & $2 \overline{--}$ & $1 \stackrel{--}{(25)}$ & $\begin{array}{l}1(6) \\
1(6)\end{array}$ & $\begin{array}{l}-- \\
--\end{array}$ & $\begin{array}{c}18(100) \\
6(33)\end{array}$ & $\begin{array}{l}1(100) \\
1(100)\end{array}$ \\
\hline ENT & -- & -- & -- & $7(44)$ & -- & -- & $1(100)$ \\
\hline Chest & -- & $1(8)$ & -- & $6(38)$ & -- & $1(6)$ & -- \\
\hline Cardiovascular & -- & -- & $1(20)$ & -- & -- & -- & -- \\
\hline Abdominal & -- & -- & -- & -- & $3(43)$ & $2(11)$ & -- \\
\hline Renal & -- & $4(33)$ & $3(60)$ & $9(56)$ & $2(29)$ & -- & -- \\
\hline Nervous system & $2(6)$ & $3(25)$ & $3(60)$ & $5(31)$ & -- & $3(17)$ & -- \\
\hline Other ${ }^{\dagger}$ & $18(53)$ & $10(83)$ & -- & $2(13)$ & -- & $4(22)$ & -- \\
\hline \multicolumn{8}{|l|}{ Diagnostic test findings } \\
\hline ANCA positivity & -- & -- & -- & $13(81)$ & -- & -- & -- \\
\hline Compatible imagiology $\ddagger$ & $27 / 33(82)$ & $12 / 12(100)$ & $4 / 5(80)$ & -- & -- & -- & -- \\
\hline Compatible biopsy $\S$ & $14 / 20(70)$ & $4 / 4(100)$ & $3 / 3(100)$ & $11 / 11(100)$ & $5 / 5(100)$ & -- & -- \\
\hline \multicolumn{8}{|l|}{ Assessments (SD) } \\
\hline BVAS v3, first visit & -- & -- & $14(7)$ & $17(8)$ & -- & -- & -- \\
\hline VDI, last visit & -- & -- & $4(0)$ & $4(2)$ & -- & -- & -- \\
\hline FFS 1996 & -- & -- & $0.3(0.4)$ & $0.4(0.7)$ & -- & -- & -- \\
\hline
\end{tabular}


Table 1 - Demographics, clinical manifestations, complementary tests findings, assessments and treatment of the patients with a diagnosis of systemic vasculitis categorized according to vessel size

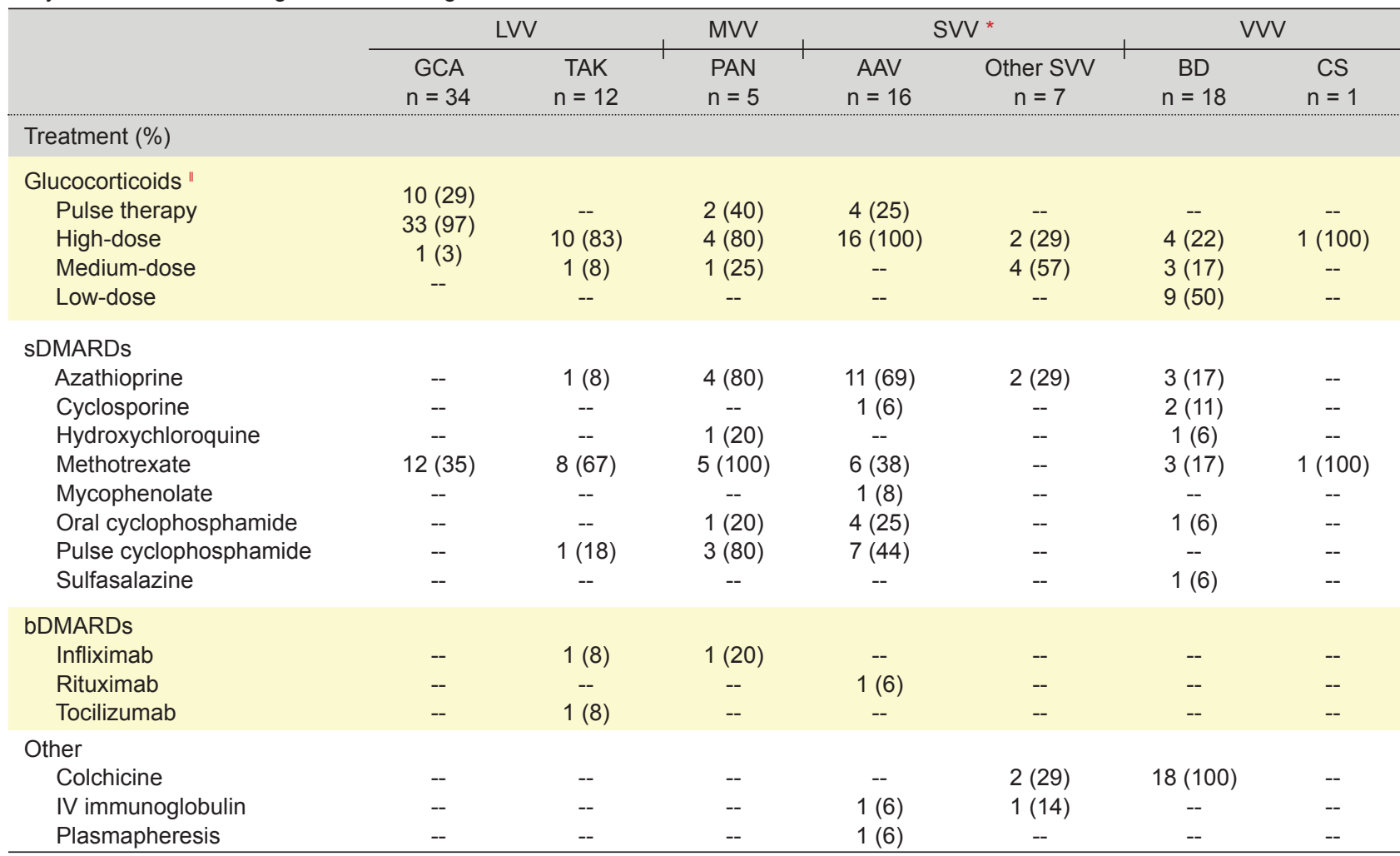

${ }^{*}$ Patients with AAV had microscopic polyangiitis $(n=6)$, granulomatosis with polyangiitis $(n=5)$, eosinophilic granulomatosis with polyangiitis $(n=4)$, and unclassifiable AAV $(n=1)$; patients with other SVV had cryoglobulinaemic vasculitis $(n=3)$, IgA vasculitis $(n=3)$, and unclassifiable SVV $(n=1)$.

${ }^{\dagger}$ The clinical manifestations are grouped according to the items listed in the BVAS v3; the ones not included in the glossary are listed as 'other'; for GCA: jaw and/or tongue claudication; for TAK: limb claudication, absent pulse and/or asymmetric pulse or blood pressure in seven patients, granulomatous hepatitis in one patient; for AAV: pulmonary hypertension in one patient, orbital pseudotumor in one patient; for VVV: superficial or deep vein thrombosis.

‡ For GCA: ultrasonography showing hypoechoic halo of the arterial wall; for TAK: angiography or computed tomography angiography showing vascular wall thickening or enhancement, occlusion of major aortic branches, aneurismal dilatation of the aorta or its branches; for PAN: angiography showing multiple microaneurysms.

§Biopsy specimen with typical histological changes. For LVV: panarteritis of the large-sized arteries with a predominance of mononuclear cell infiltration or granulomatous inflammation with or without multinucleated giant cells; for PAN: panarteritis of the medium-sized arteries with a pleomorphic cell infiltration and fibrinoid necrosis; for AAV: vasculitis of the small- to medium-sized blood vessels, without granulomatous inflammation for MPA, with granulomatous inflammation for GPA, with granulomatous inflammation and extravascular infiltration by eosinophils for EGPA, or pauci-immune segmental necrotizing glomerulonephritis; for other SVV: leukocytoclastic vasculitis of the small blood vessels, with perivascular IgA deposits for IgA vasculitis.

" Pulse therapy if parenteral administration of $\geq 250 \mathrm{mg}$ of prednisone equivalent daily, for three to five days; high-, medium- or low-dose if $>30 \mathrm{mg}$ but $\leq 100 \mathrm{mg}$, $>7.5 \mathrm{mg}$ but $\leq 30 \mathrm{mg}$, or $\leq 7.5 \mathrm{mg}$ of prednisone equivalent daily, respectively. For oral formulations only the highest dose is considered.

AAV: ANCA-associated vasculitis; bDMARDs/sDMARDs: biological/synthetic disease-modifying anti-rheumatic drugs; BD: Behçet's disease; BVAS v3: Birmingham Vasculitis Activity Score version 3; CS: Cogan's syndrome; ENT: ear, nose and throat; FFS: five-factor score; GCA: giant cell arteritis; IV: intravenous; LVV: large vessel vasculitis; MVV: medium vessel vasculitis; PAN: polyarteritis nodosa; SD: standard deviation; SVV: small vessel vasculitis; TAK: Takayasu arteritis; VDI: Vasculitis Damage Index; VVV: variable vessel vasculitis

was officially launched.

There are still no widely accepted outcome tools for disease assessment in large-vessel vasculitis (LVV) and Behçet's disease, although that is currently being looked at by the OMERACT. For LVV imaging has become particularly important. ${ }^{6}$ Ultrasound of the temporal and axillary arteries has proven effective in diagnosing GCA and has the potential to monitor disease activity. ${ }^{7,8}$ In our clinic we have been working with experienced vascular ultrasonographers to correctly diagnose and monitor our patients with LVV.

\section{Research studies and study groups}

Given the close collaboration of our group with other medical departments and research facilities, we have integrated several local and multicentric studies. For example, we participated in the TABUL study (temporal artery biopsy vs ultrasound in diagnosis of GCA) and are still recruiting for the DCVAS study (diagnostic and classification criteria for primary systemic vasculitis)..$^{7,9}$ This enabled the continuous growth of our vasculitis biobank, collaboration with the hospital Clinical Research Centre and development of other research projects within the Rheumatology Research Unit at the Instituto de Medicina Molecular.

In addition, our group has been part of the European Vasculitis Study Group (EUVAS); the OMERACT ultrasound LVV subtask force; the task force to develop the European League Against Rheumatism (EULAR) recommendations for the use of imaging in LVV; and the task force to update the EULAR recommendations for the management of LVV. 6,10 Moreover, we are currently applying for the European reference network RITA (Rare Immunodeficiency, auToinflammatory and Autoimmune diseases).

\section{FINAL CONSIDERATIONS}

The implementation of a standardized approach with regular multidisciplinary work has proven very helpful in 
evaluating patients with vasculitis and facilitating their enrolment into clinical studies. It promotes professional development of the team, easier interaction between specialties and ultimately better outcomes and patient satisfaction.

The continuous registry of patients in Reuma.pt/Vasculitis has been essential for research, patient care and healthcare planning, and the collection of blood samples from patients with vasculitis into our biobank is crucial for present and future collaborative work.

In summary, our vasculitis clinic has allowed the observation of rare diseases on a systematic basis, thus impro-

\section{REFERENCES}

1. Branco JC, Rodrigues AM, Gouveia N, Eusébio M, Ramiro S, Machado PM, et al. EpiReumaPt study group. Prevalence of rheumatic and musculoskeletal diseases and their impact on health-related quality of life, physical function and mental health in Portugal: results from EpiReumaPt - a national health survey. RMD Open. 2016;2:e000166.

2. Santos MJ, Canhão H, Faustino A, Fonseca JA. Reuma.pt: a case study. Acta Med Port. 2016;29:83-4.

3. Khmelinskii N, Ponte C, Peixoto D, Rodrigues M, Teixeira L, Sousa S, et al. AB0581 Two years existence of reuma.pt/vasculitis - the portuguese registry of vasculitis. Ann Rheum Dis. 2017;76:1254.

4. Jennette JC, Falk RJ, Bacon PA, Basu N, Cid MC, Ferrario F, et al. 2012 revised International Chapel Hill Consensus Conference Nomenclature of Vasculitides. Arthritis Rheum. 2013;65:1-11.

5. Merkel PA, Aydin SZ, Boers M, Direskeneli H, Herlyn K, Seo P, et al. The OMERACT Core Set of Outcome Measures for use in clinical trials of ANCA-associated vasculitis. J Rheumatol. 2011;38:1480-6.

6. Dejaco C. SP0095 EULAR Recommendations for the use of imaging ving quality of care and research. There is still considerable potential for clinical and scientific growth.

\section{CONFLICT OF INTERESTS}

The authors declare that the research was conducted in the absence of any commercial or financial relationships that could be construed as a potential conflict of interest.

\section{FUNDING}

No subsidies or grants contributed to this work.

in the diagnosis and management of large vessel vasculitis in clinical practice. Ann Rheum Dis. 2017;76:24.

7. Luqmani R, Lee E, Singh S, Gillett M, Schmidt WA, Bradburn M, et al. The role of ultrasound compared to biopsy of temporal arteries in the diagnosis and treatment of giant cell arteritis (TABUL): a diagnostic accuracy and cost-effectiveness study. Health Technol Assess. 2016;20:1-238.

8. De Miguel E, Roxo A, Castillo C, Peiteado D, Villalba A, Martín-Mola E. The utility and sensitivity of colour Doppler ultrasound in monitoring changes in giant cell arteritis. Clin Exp Rheum. 2012;30:S34-8.

9. Craven A, Robson J, Ponte C, Grayson PC, Suppiah R, Judge A, et al. ACR/EULAR-endorsed study to develop diagnostic and classification criteria for vasculitis (DCVAS). Clin Exp Nephrol. 2013;17:619-21.

10. Bajema IM, Bruijn JA, Casian A, Cid MC, Csernok E, van Daalen E, et al. The European Vasculitis Society 2016 Meeting Report. Kidney Int Rep. 2017;2:1018-31. 